\title{
LETTERS
}

Send your letters to the Editor, British Dental Journal, 64 Wimpole Street, London W1G 8YS E-mail bdj@bda-dentistry.org.uk

Priority will be given to letters less than 500 words long. Authors must sign the letter, which may be edited for reasons of space.

\section{Fruit juice and dried fruit - healthy choices or not?}

Sir,- I found Dr Moynihan's article (BDJ 2002; 193: 563-568) on dietary advice in general dental practice a model of clarity, in an area that suffers from public confusion and experts apparently disagreeing with each other ${ }^{1}$. However, I am concerned that the messages given by Dr Moynihan may conflict with the Government's advice on increasing children's fruit and vegetable consumption.

There is no dispute between dentists and nutritionists about the desirability of consuming whole fruit between meals, as a means of reaching the Department of Health's five portions a day target, but the crunch seems to come when considering fruit juice and dried fruit as suitable alternatives. Dr Moynihan states that fruit juice is both potentially cariogenic and capable of causing erosion, and that dried fruit is likely to be more cariogenic than fresh fruit. However, the Department of Health's guidance on the School Fruit Scheme ${ }^{2}$ lists both fruit juice and dried fruit as portions that count towards the target accompanied by photographs of these products. The Food Standards Agency meanwhile ${ }^{3}$ cautions against fruit juice between meals for children, but enthusiastically states that "dried fruit is a healthy choice if you want a snack, because it's full of fibre and vitamins'.

Would Dr Moynihan and/or the Department of Health like to comment on whether schools should or should not offer or encourage the consumption of fruit juice and dried fruit at school break-times? I suspect that oral health promotion professionals liaising with schools at a local level might find this helpful.

\section{Stillman-Lowe \\ Reading}

1. Stockley L (1993). The promotion of healthier eating: a basis for action. London, Health Education Authority.

2. Department of Health (2000). The National School Fruit Scheme. London, Department of Health.

3. Food Standards Agency web-site: www.foodstandards.gov.uk

\section{Dr Moynihan responds:-}

The consumption of fruit and vegetables by school children in the UK is undesirably low $w^{1}$ and the School Fruit Scheme as a means to address this is commendable and welcomed. However, the letter received from Catherine Stillman-Lowe has raised an important question as to whether fruit juice and dried fruit should be encouraged as choices for the School Fruit Scheme. For schools these may be preferable choices over fresh fruit due to advantages of a prolonged shelf life and the guaranteed quality of the product. However, from a dental health perspective these items are not desirable and for the Department of Health to be encouraging their use in the School Fruit Scheme conflicts with other Department of Health advice concerning dental health.

The Committee on Medical Aspects of Food Policy report 'Dietary sugars and Human Disease'2 clearly recommends that the consumption of NME sugars should be decreased and replaced with fresh fruit, vegetables and starchy staple foods. It also states that those providing food for communities should seek to reduce the frequency with which 'sugar snacks' are consumed. Despite this report being over a decade old it has not been superseded and other expert reports likewise recommend that intake of NME sugars should be reduced and avoided between mealtimes ${ }^{3,4}$.

The Food Standards Agency (FSA) state that fruit or vegetable juice may contribute one portion towards the recommended five a day; so regardless of how much is consumed, fruit/vegetable juice may only count as one portion. This is because fruit/vegetable juice does not contain all the beneficial plant cell wall materials and non-starch polysaccharide (fibre) that whole fruits and vegetables do.

Fruit juices contain approximately 10\% NME sugars and dried fruits are approximately $70 \%$ sugars. The method used by the FSA to estimate the NME sugars content of foods, assumes that $50 \%$ of sugars in dried fruits are NME sugars (personal communication), therefore dried fruit (e.g. raisins) are approximately 35\% NME sugars; a level comparable with sugared breakfast

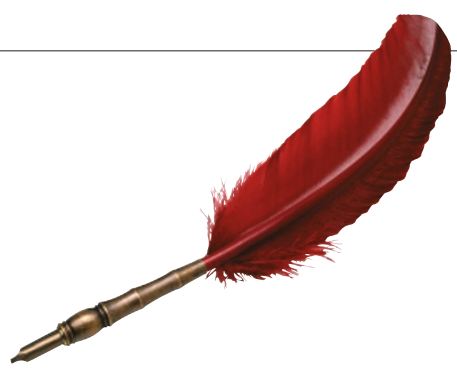

cereals, biscuits and cakes and certainly a level high enough to classify dried fruit as a 'sugar snack'. It is clear therefore that in order to follow current recommendations for dental health, that fruit juices and dried fruits should not be encouraged as part of the School Fruit Scheme.

\section{P. Moynihan}

Newcastle

1. Gregory J and Lowe S (2000). National Diet and Nutrition Survey: young people aged 4-18 years. Volume 1: report of the diet and nutrition survey. London: The Stationery Office.

2. Department of Health (1989). Dietary sugars and human disease. Report on Health and Social Subjects No 37. HMSO

3. Department of Health (1991). Dietary reference values for food energy and nutrients in the UK. Report on Health and Social Subjects No 41. HMSO.

4. Health Development Agency (2001). The Scientific Basis of Dental Health Education. In Dental Profile, August 2001. www.dpb.nhs.uk.

\section{Warfarin and extraction}

Sir,- I read with interest the recent correspondence from A J Gibbons et al on Warfarin and extraction (BDJ 2002; 193: 302).

The Community Dental Service in Sunderland has routinely been treating Warfarin patients since 1998, doing no more than three simple extractions on usually stoical older people. Warfarin is never stopped. An INR level of four is set. Sutures and surgicel are always used, and there have been no significant problems. We can have an INR result, from venepuncture, within an hour.

There is really no need to involve costly hospital departments - we use peripheral clinics. We have easy access to a haematology laboratory, which would be awkward for a GDP. I do not use an electronic photometer, because I have a tendency to break machines and there is a certain pleasure in playing at doctors! More seriously, some haematologists distrust them and, seeing as they would be expert witnesses in any clinical negligence action, this is important.

I would welcome colleagues' opinion on this.

\section{R. H. Balderston} Sunderland 


\section{Web-based learning}

Sir,- Holt and Oliver ${ }^{1}$ recently described a novel part of a course in dental public health. That course combined both webbased and traditional methods of teaching and learning. It concluded that web-based learning might not be suitable for all students.

A new course ${ }^{2}$ that reflects modern advances in both the content and delivery of postgraduate education in dental public health has been launched early this year. It is designed as one of the course units of the first web-based public health masters programme in the UK - Masters in Population Health Evidence (MPHe) ${ }^{3}$. The small 'e' in the title also represents the electronic mode of delivery.

Students benefit from the advantages of web-based delivery such as increased flexibility and control over the timing of their learning, simple navigation and links both within course material and to the vast amount of resources now available on the world wide web.

The advent of new web-based technology allows the course to be delivered to those who find face-to-face contact difficult for reasons of geography, employment or personal circumstances. This does not mean that teachers and students will not get to know each other. The short residential components, the e-mail discussion groups and the discussion boards which form essential parts of the course ensure that contact is maintained between teachers and students and among the student groups.

I believe we are way behind the curve at this point when it comes to web-based learning for the dental profession. As the technology develops further, the opportunities are even more vast and exciting. Wireless broadband is already making many features of the internet feasible via personal digital assistants that have tremendous implications for education and patient care in dentistry. I truly hope the early adopters and innovators continue to work against the tremendous inertia that is preventing dentistry from taking full advantage of web-based learning.

\section{A. Yeung}

\section{Manchester}

1. Holt R D, Oliver M. Evaluating web-based learning modules during an MSc programme in dental public health: a case study. Br Dent J 2002; 193: 283-286.

2. University of Manchester Evidence for Population Health Unit. Masters in Population Health evidence/electronic. (http://www.mphe.man.ac.uk)

3. Edwards R, Heller D, McElduff P, McDevitt M, Humphrey A, Pappashinopoulos C. University of Manchester MPHe - A Web-based Masters in Population Health Evidence. Internet J Public Health Educ 2002; 4: B22-33.

(http://wxvw.healthplatform.de/cweb/designlfs.icom?i $d=4)$

\section{Watching and waiting}

Sir,- In March 2000 the National Institute for Clinical Excellence (NICE) published guidelines on the removal of wisdom teeth. The Appraisal Committee determined that there was no reliable research to support a health benefit to patients from the prophylactic removal of pathology-free impacted third molar teeth, and that the removal of these teeth exposed patients to unnecessary surgical or anaesthetic complications. We would like to draw your readers' attention to a case that suggests even in the presence of asymptomatic pathology, a prudent watch and wait policy may be considered in the case of an anticipated difficult surgical extraction.

A 41-year-old male was referred for the assessment of lower left wisdom tooth roots retained following an unsuccessful attempt at extraction. The OPG demonstrated unfavourable root morphology and close proximity of the roots to the inferior alveolar nerve (Fig. 1). Since the patient was asymptomatic and in light of the radiographic findings, surgical intervention was delayed.

Three years later the patient began to experience recurrent infections associated with the wisdom tooth roots in the lower left quadrant. An OPG at this time demonstrated that the roots had "erupted" further (note new bone formation adjacent to roots), had a more favourable root morphology and were no longer in close proximity to the inferior alveolar nerve (Fig. 2). The roots were removed without complication under local anaesthesia.

\section{T. Martin and S. Dover}

\section{West Midlands}

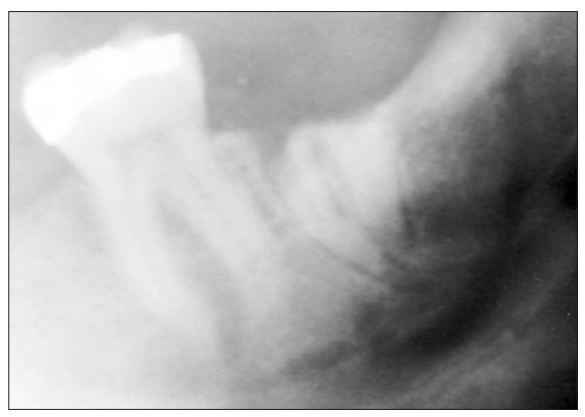

Figure I.

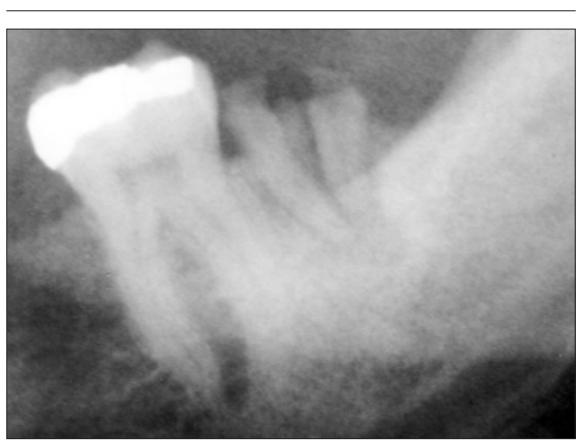

Figure 2. 